\title{
VENTILATION IN PATIENTS ANAESTHETIZED FOR LAPAROSCOPY
}

\author{
John DESMOND, M.B., B.S., F.R.C.P.(C), AND \\ R. A. GoRDON, M.D., F.R.C.P.(C), F.F.A.R.C.S."
}

INTRAPERITONEAL ENDOSCOPY, now referred to as laparoscopy, has been performed intermittently since the beginning of this century. Renon, a surgeon from Paris, published a paper on the technique of and indications for laparoscopy as long ago as 1913. Its use as a means of visualizing the abdominal organs was never popular until Steptoe in $1964^{1-2}$ published a large series of cases showing that the technique was a valuable addition to the armamentarium of the gynaecologist and general surgeon. Eighteen months ago, Steptoe demonstrated the use of this instrument at the Toronto General Hospital. At the time, one of us who was fortunate enough to be present showed some concern about what was happening to the large quantity of carbon dioxide which was introduced into the peritoneal cavity, particularly as the patient was breathing spontaneously on nitrous oxide and halothane anaesthesia and was maintained in a steep Trendelenburg position. On being questioned, Steptoe stated that this was the technique used by his anaesthetists in England and that they had not had any problems. Six months later, laparoscopy became a routine procedure in our hospital, and reports of bigeminal rhythm in several cases and a cardiac arrest (successfully resuscitated) prompted us to set up a study to determine, firstly, whether spontaneous ventilation might be dangerous for these patients and, secondly, if so, what the anaesthetic technique of choice should be for this procedure.

\section{Brief Description of the Procedure}

Following the induction of anaesthesia, the surgeon introduces 3 to 5 litres of carbon dioxide into the peritoneal cavity, making sure that the pressure of the gas within the cavity at no time exceeds $25 \mathrm{~mm} \mathbf{H g}$. A large trocar is then introduced through the abdominal wall, and through this the laparoscope is passed. The patient is placed in the Trendelenburg position $\left(15-20^{\circ}\right)$ to move the abdominal viscera up towards the diaphragm, thus leaving the pelvic organs free to be visualized by the surgeon. The procedure lasts from one-half to one hour, depending on whether or not the surgeon decides to do one of the several additional operations now possible with the use of the laparoscope. A small amount of carbon dioxide is permitted to flow into the peritoneal cavity throughout the procedure, to compensate for any leakage that might occur in and around the laparoscope. At the end of the procedure all the carbon dioxide is evacuated through the scope.

'From the Department of Anaesthesia, University of Toronto and the Toronto General Hospital. 


\section{Method and Materials}

A total of 14 patients selected randomly from the gynaecological service were studied in this series. Ten of the patients (groups I and II) were permitted to breathe spontaneously throughout the study. Induction of anaesthesia was with thiopentone, and maintenance of anaesthesia in this group of patients was carried out with nitrous oxide, halothane ( $1 / 2-1$ per cent) and oxygen ( 33 per cent). All the patients were intubated and a non-rebreathing system (Sierra valve) was used in each case. A Wright spirometer on the expiratory side of the valve was used to measure tidal and minute volumes.

Arterial samples were taken for blood gas analysis at induction of anaesthesia and at 5, 15, and 25 minutes following the insufflation of the carbon dioxide into the peritoneal cavity. In five patients (group r) all expired gases were collected in a Douglas bag, both before and after the insufflation of the carbon dioxide. Electrocardiographic monitoring was instituted in all cases. Two patients (group III) were curarized and ventilated by the Radford nomogram and another two patients (group rv) were hyperventilated.

\section{Analysis of Results}

\section{Group I}

1. The pre- and post-insufflation expired gas collections showed that four of the patients produced $66-133 \mathrm{ml}$ of carbon dioxide per minute more following the insufflation than before.

2. Minute volumes increased from 50 to 100 per cent during the post-insufflation period.

3. A significant change in respiratory rate following the insuffation was also noted.

4. One patient developed bigeminal rhythm and multi-focal ventricular contractions shortly after the insufflation of the carbon dioxide. The arrhythmia lasted for eight minutes even though the patient was immediately given 100 per cent oxygen.

5. Analysis of the blood gases showed a rise in arterial $\mathrm{Pa}_{\mathrm{CO}_{2}}$ to $59 \mathrm{~mm} \mathrm{Hg}$ in case no. 3 .

6. There appeared to be some respiratory and metabolic acidosis present during the post-insufflation period.

7. Low $\mathrm{Pa}_{\mathrm{O}_{2}}$ (46-64 $\mathrm{mm} \mathrm{Hg}$ ) was noted in case no. 4 of this group.

\section{Group II}

In this group, minute volumes and respiratory rates were recorded frequently with a Wright spirometer, which was attached to the expiratory side of the Sierra valve. Arterial blood gases were taken at the times specified earlier.

1. Two patients in this group had tidal volumes (VT) of $90 \mathrm{cc}$.

2. Respiratory rates increased during the post-insufflation period by 75 to 100 per cent, probably accounting in part for the high minute volumes noted in three of the five cases. 


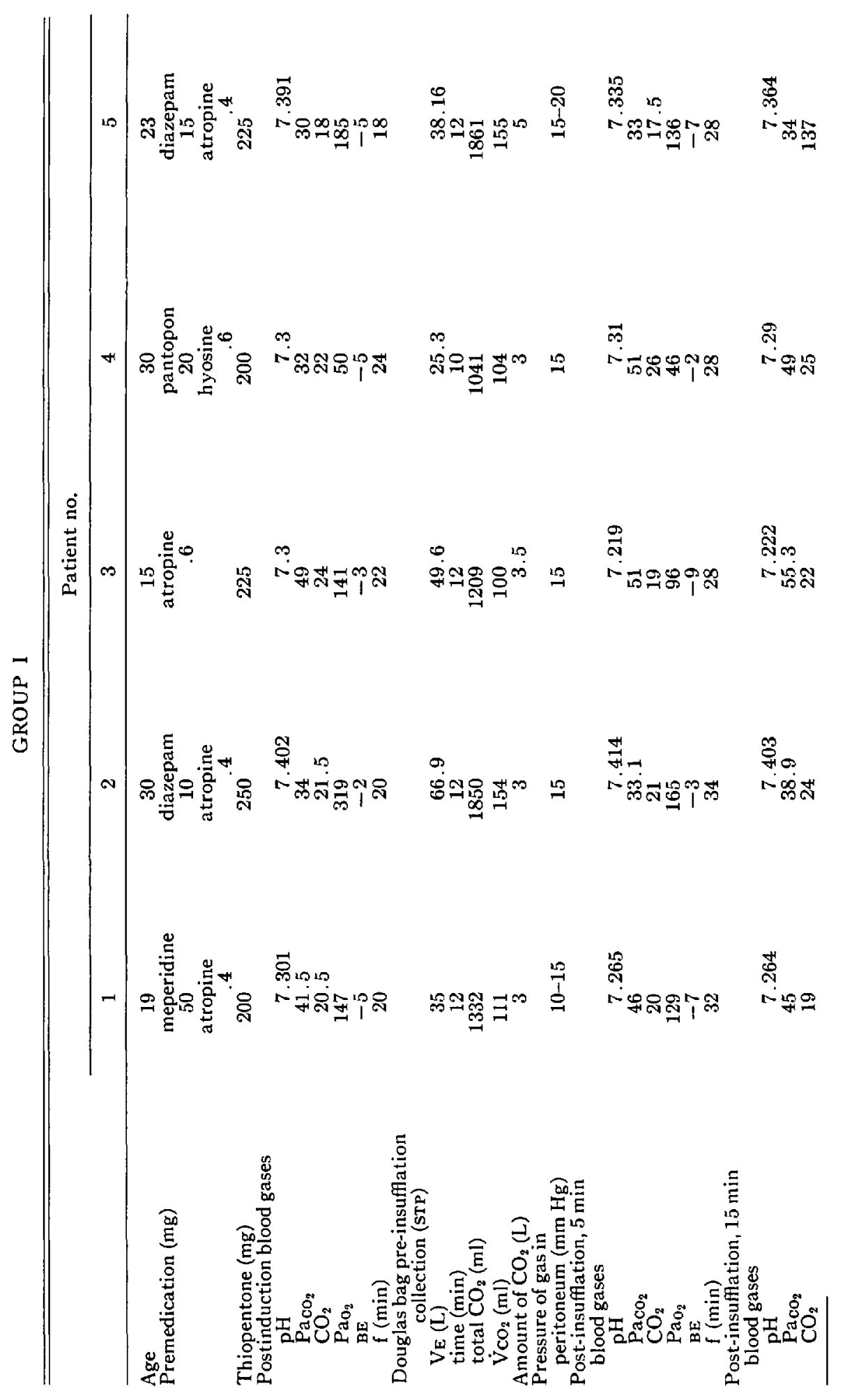




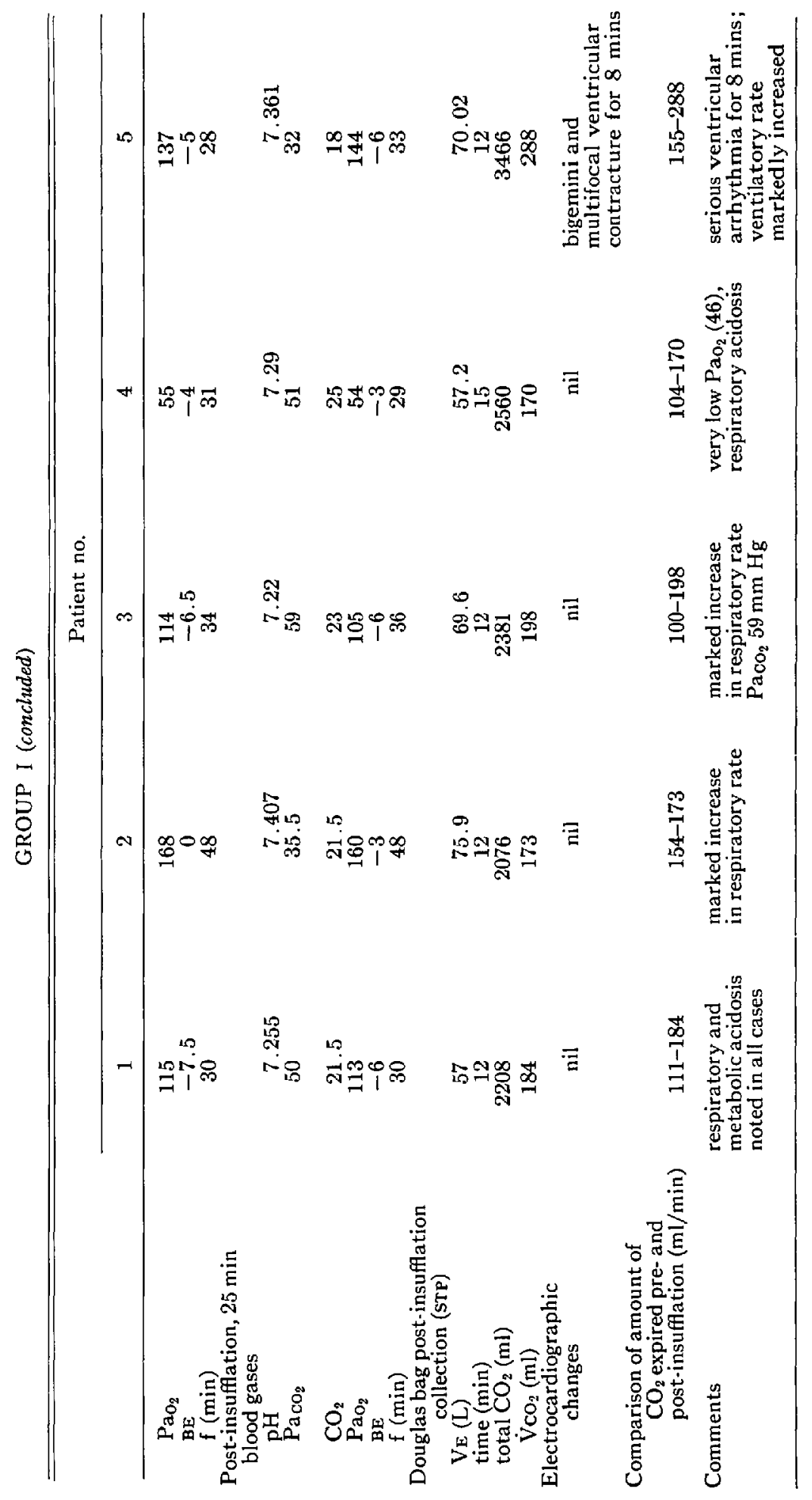




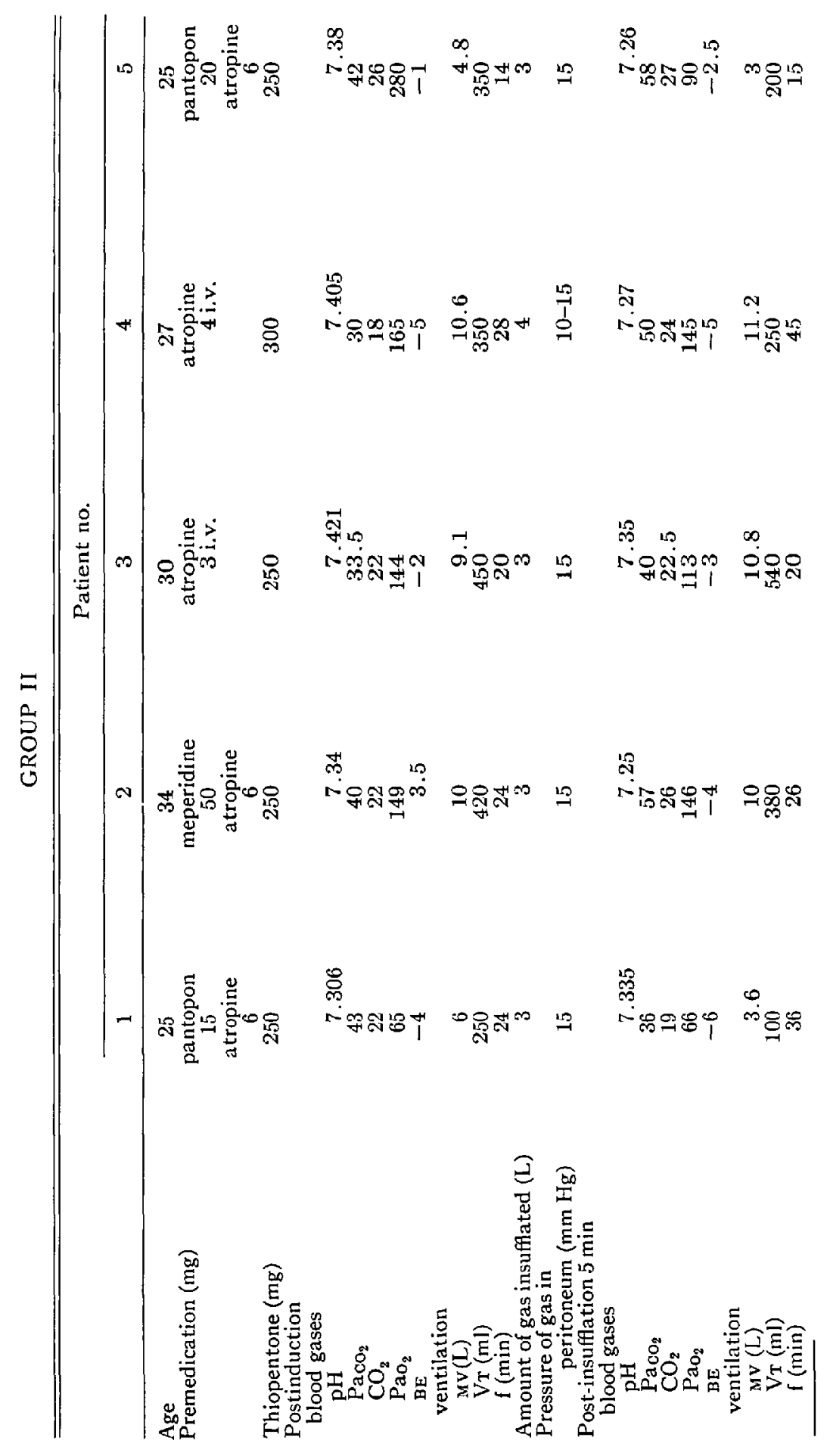




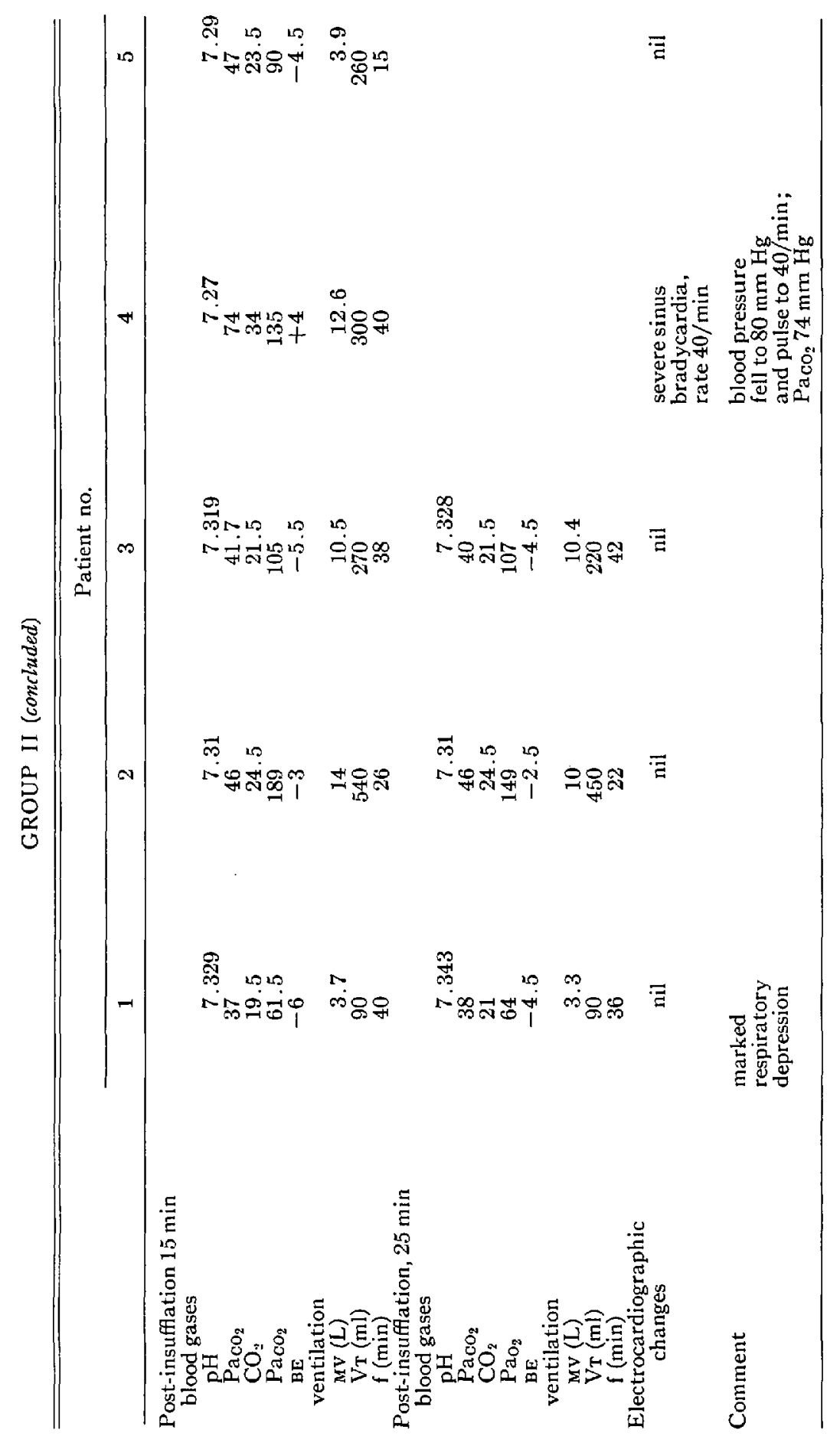


3. One patient in this group showed a rise in arterial $\mathrm{Pa}_{\mathrm{CO}_{2}}(74 \mathrm{~mm} \mathrm{Hg})$. The blood pressure fell to $80 \mathrm{~mm} \mathrm{Hg}$ systolic and sinus bradycardia also occurred $(40 / \mathrm{min})$. Fortunately, the procedure terminated soon after this serious state of affairs developed. The blood pressure and pulse rate returned to normal soon after the carbon dioxide had been evacuated from the peritoneal cavity.

4. Some degree of respiratory and metabolic acidosis was also noted in this group.

\section{Group $\amalg$}

The two patients in this group were paralysed, and ventilatory volumes were set by the Radford nomogram. Only slight post-insufflatory increases in arterial $\mathrm{Pa}_{\mathrm{CO}_{2}}$ were noted in these patients. The reason for including this group in the series will be elaborated later in the discussion.

\section{Group IV}

Hyperventilation was used for both patients in this group.

1. The falls in arterial $\mathrm{Pa}_{\mathrm{CO}_{2}}$ were predictable.

2. Respiratory alkalosis was seen in both patients.

3. No changes in blood pressure or pulse rate were noted.

\section{Discussion}

Probably the most significant finding to come out of this study is that a large amount of the insufflated carbon dioxide is eventually excreted through the lungs. This being so, a patient who is under-ventilating because of the steep Trendelenburg position and splinted diaphragm might be unable to get rid of the carbon dioxide. The resulting changes in the arterial $\mathrm{pH}$ and $\mathrm{Pa}_{\mathrm{CO}_{2}}$ must be considered dangerous when halothane is being used in these cases.

The observations in groups I and II indicate that it may be extremely hazardous to permit these patients to ventilate spontaneously. Controlled ventilation is also unsatisfactory if the volumes used are too low, as was the case with the patients in group III. Although we saw no untoward changes in this group, one must suspect that the arterial $\mathrm{Pa}_{\mathrm{CO}_{2}}$ could rise to critical levels. We feel that the patients in the hyperventilated group probably received the best anaesthetic management.

Several other problems and questions must be considered:

1. To what extent is the insufflated gas in the peritoneal cavity $(15-25 \mathrm{~mm} \mathrm{Hg}$ ) interfering with venous return?

2. Hyperventilation, which we are suggesting as necessary to eliminate the excess carbon dioxide in these patients, will also depress the venous return and the cardiac output, and must therefore be carried out with caution. ${ }^{3}$

3. The anaesthetist must be constantly aware that carbon dioxide embolism, visceral perforation, and haemorrhage might occur and lead to severe cardiovascular collapse. Perforation of the bowel occurred in one case not included in our series. This patient had had several previous operations, resulting in extensive intra-abdominal adhesions. At the laparotomy which had to be carried out in this case, four perforations were found in the intestine. The rapid onset of 
GROUP III

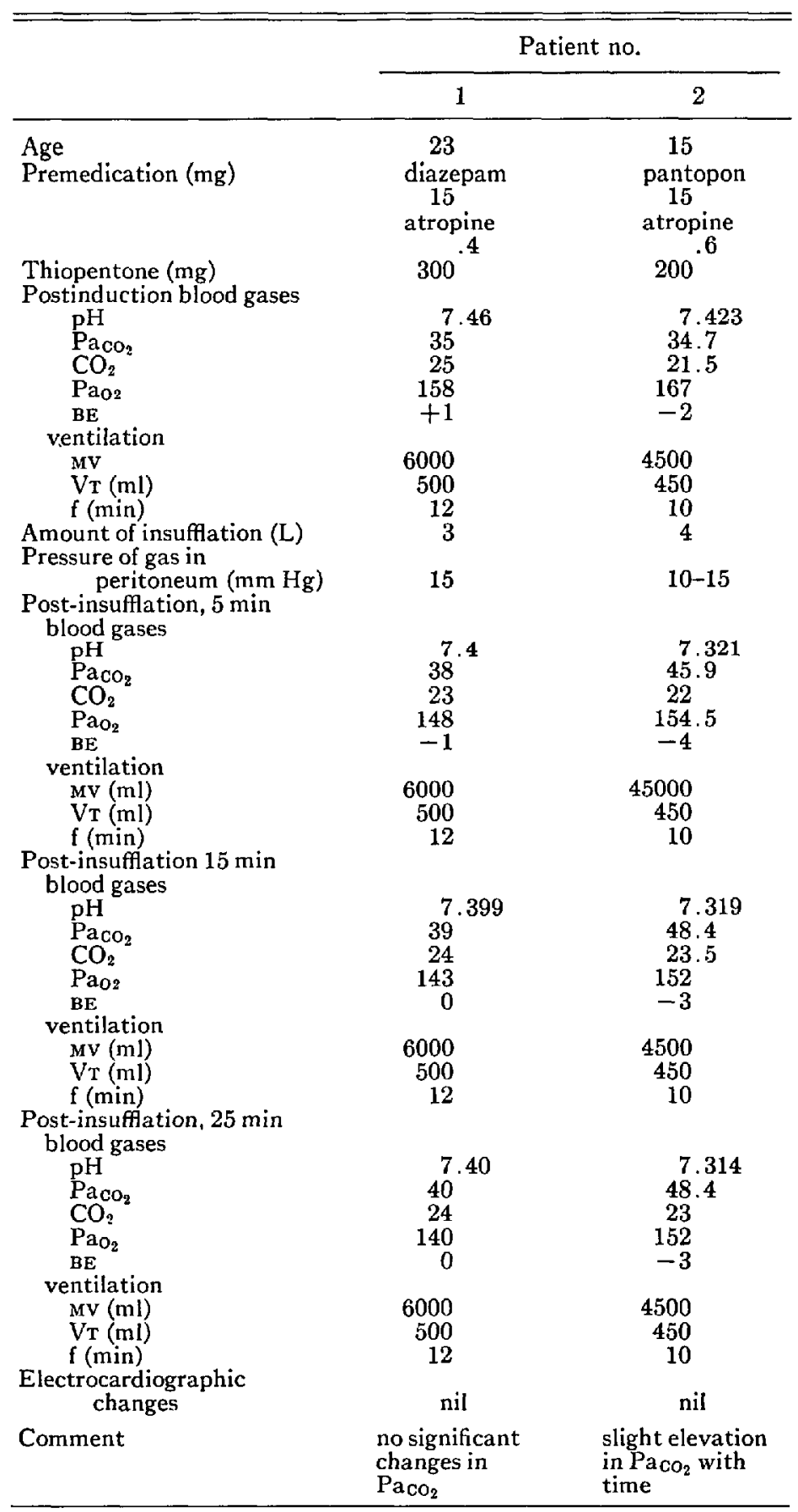


GROUP IV

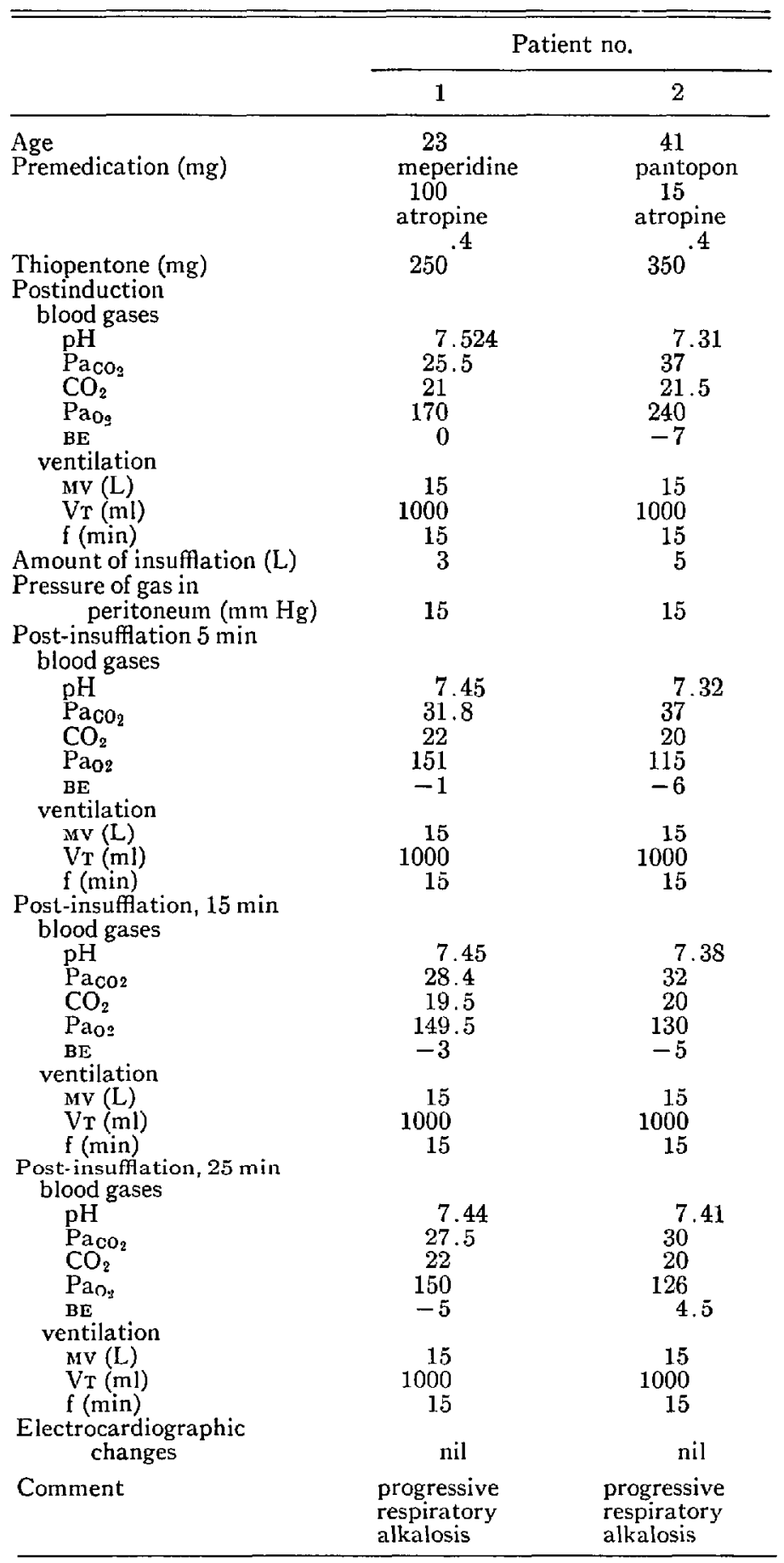


shock due to perforation in patients who have had previous surgery must be closely watched for at all times. Constant monitoring of these patients is therefore essential.

4. Brown et al. ${ }^{4}$ showed that there is severe respiratory impedance following the insufflation of the carbon dioxide even in the ventilated patient. In four cases where a chest X-ray was taken at the times of insufflation we found the diaphragm to be considerably elevated, and this probably accounted for the low tidal volumes seen in some of the patients who were breathing on their own throughout the procedure. We are not able to give any explanation for the metabolic acidosis seen in these patients. However, the venous stagnation which occurs in the upper portion of the body in this steep position could have contributed in part to metabolic acidosis.

\section{SUMMARY}

Spontaneous ventilation during laparoscopy is dangerous and must be condemned. Adequate controlled ventilation, sufficient to remove the carbon dioxide being excreted by the lungs, must be instituted in all cases. Some of the more serious complications peculiar to this procedure have been discussed, as these directly affect the anaesthetic management of these patients. These include reduction of cardiac output by impedance of venous return, carbon dioxide embolism, visceral perforation, and haemorrhage.

\section{RéSUMÉ}

La ventilation spontanée durant la laparoscopie est dangereuse et condamnable. Il faut dans tous les cas pratiquer une ventilation controlée convenable, suffisante pour éliminer l'acide carbonique excrété par les poumons. On a étudié quelques unes des plus sérieuses complications particulières à cette intervention, et toutes concernent directement la conduite de l'anesthésiste envers ces malades. Parmi ces complications, notons la diminution du débit cardiaque, l'embolie à l'acide carbonique, la perforation viscérale et l'hémorragie.

\section{REFERENCES}

1. Steptoe, Patruck C. Laparoscopy in Gynaecology. E. S. Livingstone Ltd. (1967).

2. Steptoe, Patrick C. Gynaecological Endoscopy: Laparoscopy and Culdoscopy. J. Obst. \& Gynaec. (British Commonwealth). 72: 535 (1965).

3. Seed, R. F.; Shakespeane, T. F.; \& Muldoon, M. J. Carbon Dioxide Homeostasis during Anaesthesia for Laparoscopy. Anaesthesia. 25: no. 2 (1970).

4. Gaylord, D. Alexander; Frances, E. Noe; \& Brown, Eli M. Pelvic Laparoscopy. Anesth. \& Analg. 48 (1969). 